\title{
Thermal Diffusivity During Water Bath Cooking of Breadfruit (Artocarpus communis)
}

\author{
Diego F. Tirado ${ }^{1 *}$, Diofanor Acevedo-Correa ${ }^{2}$, Piedad M. Montero-Castillo ${ }^{3}$, Shirley Cavadia-Puello ${ }^{4}$ \\ Diana C. Mantilla-Escalante ${ }^{5}$ \\ ${ }^{1}$ Department of Chemical Engineering, School of Chemistry, Universidad Complutense de Madrid, Av. \\ Complutense s/n, 28020, Madrid, Spain. \\ e-mail: ditirado@ucm.es. \\ ${ }^{2}$ Research Group Nutrición Salud y Calidad Alimentaria (NUSCA), Universidad de Cartagena, Av. El \\ Consulado, St. 30 No. 48-152. Cartagena de Indias, Colombia. \\ ${ }^{3}$ Department of Food Engineering, School of Engineering, Research Group Nutrición Salud y Calidad \\ Alimentaria (NUSCA), Universidad de Cartagena, Av. El Consulado, \\ St. 30 No. 48-152. Cartagena de Indias, Colombia. \\ ${ }^{4}$ Department of Pharmaceutical Chemistry, School of Pharmaceutical Sciences, Universidad de Cartagena, \\ Campus of Zaragocilla, Cartagena de Indias, Colombia. \\ ${ }^{5}$ Departament of Applied Physical Chemistry, School of Science, Universidad Autónoma de Madrid, \\ C/ Francisco Tomás y Valiente $\mathrm{N}^{\circ} 7$, Madrid, Spain.
}

\begin{abstract}
Breadfruit is a fruit originated from South Pacific, and afterwards, it was widespread in the rest of Oceania. In Colombia, it is known as "Fruta de pan" and in-home use, breadfruit has been consumed cooked, fried or roasted. The optimisation of water bath cooking could reduce the energy cost of these operations; therefore, this study aimed to determine the thermal diffusivity during the process of boiling baking cylinders of breadfruit. The process was carried out using a temperature controlled water bath designed for this purpose at $95{ }^{\circ} \mathrm{C}$. The method used for the determination of diffusivity was based on the analytical solution of the heat transfer by conduction equation written in cylindrical coordinates. We found a thermal diffusivity value of $6.4510^{-7} \mathrm{~m}^{2} / \mathrm{s}$, which was within the range of values reported by other authors, although not in the product studied, since there were no previous studies on this matter for the breadfruit.
\end{abstract}

Keywords: Fruta de pan, Heat transfer, Conduction, Time-temperature profiles, Native products.

\section{INTRODUCTION}

Artocarpus communis, commonly known as breadfruit tree because of the "bread-like texture" of its edible fruits, is an equatorial lowland species of flowering tree in the mulberry family (Moraceae), which has about 50 genera and over 1000 species that grows best below elevations of $650 \mathrm{~m} \mathrm{[1].} \mathrm{A.} \mathrm{communis} \mathrm{is} \mathrm{a} \mathrm{fruit} \mathrm{tree} \mathrm{that} \mathrm{is}$ propagated by the root cuttings and the average age bearing the first crop is between 4 and 6 years. It produces its fruit up to 2-3 times in a year, and the number of fruits produced is very high. The fruit is aromatic, rich in latex and can weigh between $1 \mathrm{~kg}$ and $4 \mathrm{~kg}$ [2]. Breadfruit is a fruit originated from South Pacific, and afterwards, it was widespread in rest of Oceania. In Colombia, it is known as "Fruta de pan" and in-home use, breadfruit has been consumed cooked, fried or roasted [3], [4]. A. communis is edible and a valuable natural resource due to its high content of nutrients $(84.2 \%$ carbohydrates, $4.1 \%$ proteins, $3.5 \%$ fibre and $2.9 \%$ minerals in dry weight) [5].

Water bath cooking is a wet cooking process, where the maximum water temperature is $100{ }^{\circ} \mathrm{C}$ at 1 bar, or under other pressure conditions [6]. The choice of cooking process parameters should represent an acceptable compromise between sensorial quality, microbiological quality and energy use [7]. Concerning the latter, optimising this type of process could reduce the energy cost of these operations, so it is of interest in engineering [8]. To control and optimise cooking operations, fundamental physical processes and physical properties must be analysed and estimated. Several studies have been devoted to studying the cooking process of some products, mostly meat and starchy products [6], [9]-[11].

There are no data related to the cooking of breadfruit; therefore, the objective of this work was to study the diffusivity during the cooking process of cylinders of A. communis from San Andrés Island (Colombia), looking for generating a calculation of thermal diffusivity. 


\section{MATERIALS AND METHODS}

\section{A. Raw material}

The breadfruit (A. communis) was obtained from the Central Market of San Andrés Island (Colombia) in a commercially mature state, healthy and free of fungi and weevil. The peel was removed and cut in the shape of a cylinder $10 \mathrm{~cm}$ long and $3 \mathrm{~cm}$ in diameter.

\section{B. Cooking procedure}

Cooking processing operations were carried out using a temperature controlled water bath built and designed at our laboratory for this purpose following the same specifications used by Ayadi et al., [6]. For this, J-type thermocouples were used to determine the time-temperature history of samples during cooking. One thermocouple was placed in the bath water to measure the process temperature. The second thermocouple was fixed at the geometric centre of the sample. The third one was placed just under the sample surface, at a maximum depth of $0.5 \mathrm{~mm}$. At the beginning of the experiment, samples were placed in the water bath at $95{ }^{\circ} \mathrm{C}$ $\pm 1{ }^{\circ} \mathrm{C}$. The water in the unit was not stirred during cooking. When the temperature at the centre of the sample had increased to the desired value (between $72{ }^{\circ} \mathrm{C}$ and $76^{\circ} \mathrm{C}$ ), the sample was removed from the hot water. Temperature changes in the water bath $\left(\mathrm{T}_{\infty}\right)$, sample centre $\left(\mathrm{T}_{\mathrm{C}}\right)$ and on the sample surface $\left(\mathrm{T}_{\mathrm{S}}\right)$ were monitored every $2 \mathrm{~min}$. The water to sample ratio was 6 to 1 .

\section{Thermal diffusivity determination}

To simplify the problem, the sample was modelled as a finite cylinder with radius $\mathrm{R}$ and length $2 \mathrm{~L}$. The method used was based on the analytical solution of the conduction heat transfer equation written in cylindrical coordinates. This method was described and applied by Ayadi et al., [6] to measure the thermal diffusivity of salami and ham products prepared from turkey meat. The method assumes a constant sample surface temperature $\left(T_{S}\right)$ and constant thermal diffusivity. If the initial temperature distribution $\left(T_{0}\right)$ is uniform, the exact solution of the conduction heat transfer equation written in cylindrical coordinates is described by Equation (1).

$\frac{T_{s}-T}{T_{s}-T_{0}}=\sum_{m=1}^{\infty} \sum_{n=1}^{\infty} \frac{2(-1)^{m+1}}{\beta_{m}} \operatorname{Cos}\left(\frac{\beta_{m} z}{L}\right) \frac{2 J_{0}\left(\beta_{n} r / R\right)}{\beta_{n} J_{1}\left(\beta_{n}\right)} x \exp \left\lfloor-\left(\frac{\beta_{n}^{2}}{R^{2}}+\frac{\beta_{m}^{2}}{L^{2}}\right) \alpha t\right\rfloor$

If the sample is exposed to the temperature difference for a long time, Equation (1) can be reduced to the first term of the series. For $\mathrm{m}=\mathrm{n}=1, \beta_{\mathrm{m}}=\pi / 2, \beta_{\mathrm{n}}=2.405, \mathrm{~J}_{1}(2.405)=0.519$, and at the centre of a cylindrical sample $\mathrm{z}=0, \mathrm{r}=0$ and $\mathrm{J}_{0}(0)=1.0$. The temperature change at the central point of the sample in the case of long exposure to external temperatures is then given by Equation (2).

$\operatorname{Ln}\left|T_{s}-T_{c}\right|=\operatorname{Ln}\left(2.0396\left|T_{s}-T_{0}\right|-\left\lfloor\left(\frac{2.405}{R}\right)^{2}+\left(\frac{2 \pi}{L}\right)^{2}\right\rfloor \alpha t\right.$

Then, thermal diffusivity can be calculated by using Equation (4). Equation (2) is linearly time-dependent and can be transformed to the equivalent linear form as Equation (3) shows with slope B and intercept A. The thermal diffusivity then can be calculated from Equation (4).

$\operatorname{Ln}\left|T_{s}-T_{c}\right|=A-B t$

$\alpha=B\left\lfloor\left(\frac{2.405}{R}\right)^{2}+\left(\frac{2 \pi}{L}\right)^{2}\right\rfloor-1$

B can be calculated from experimental data using linear regression. The temperature of the water bath during cooking was assumed to be constant. 


\section{RESULTS AND ANALYSIS}

\section{A. Time-temperature profiles and thermal diffusivity estimation}

Fig. 1 shows the thermal history of breadfruit samples during the cooking process. The thermal centre of the product recorded with the thermocouples showed a linear temperature increase, reaching $75^{\circ} \mathrm{C}$ in $1 \mathrm{~h}$. This was most likely because the maximum internal energy within the sample was achieved [4]. Other authors obtained similar results for this temperature change in the centre of the sample of different foodstuffs [6], [9], [12], [13]. On the other hand, the surface temperature increased rapidly at the beginning of the process, stabilising at temperatures close to $90{ }^{\circ} \mathrm{C}$. This means that the gelatinisation of starches started at nearby points from the surface of the sample shortly after the start of the cooking process and lasted almost to the end until the temperature of the points found near the axes reached the temperature of the cooking medium [6], [13].

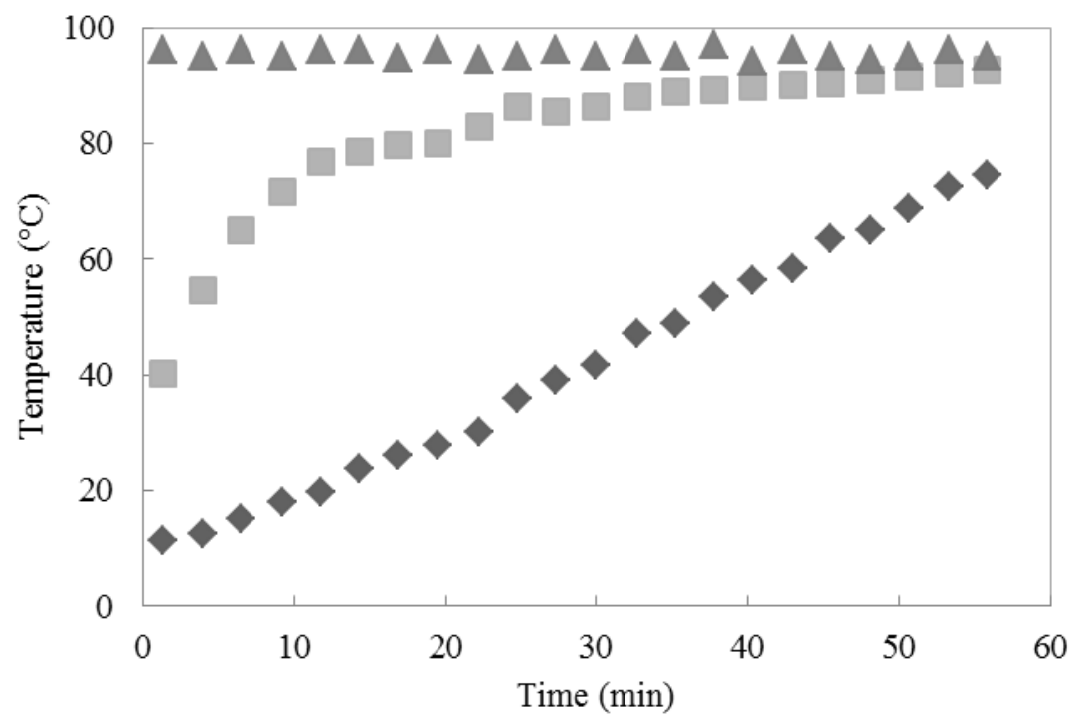

Fig. 1. Time-temperature profiles obtained during cooking of breadfruit in the water bath $(\Delta)$, sample centre $(\bullet)$ and on the sample surface (

Ayadi et al., [6], in their work of determination of thermal diffusivity and salami and ham products prepared from turkey meat, recommended stopping cooking processing when a final internal temperature of $74{ }^{\circ} \mathrm{C}$ was reached. These authors found that between $35 \mathrm{~min}$ and $45 \mathrm{~min}$ the internal temperature of samples was close to $75^{\circ} \mathrm{C}$, just as it was evidenced in this work.

On the other hand, Fig. 2 shows a typical temperature profile over time (on a semi-log plot scale) obtained in this study. The adjustment of Equation (3) shows a curvilinear part at the beginning of the process, followed by a linear region, as reported by other authors [4], [6], [13]. On the other hand, Carciofi et al., [9] in their baking study of mortadella observed two periods with different slopes, which was not found in the present study, possibly due to differences in the internal heat resistance of each type of material, as it has been reported by Tirado et al., [4], [7]. 


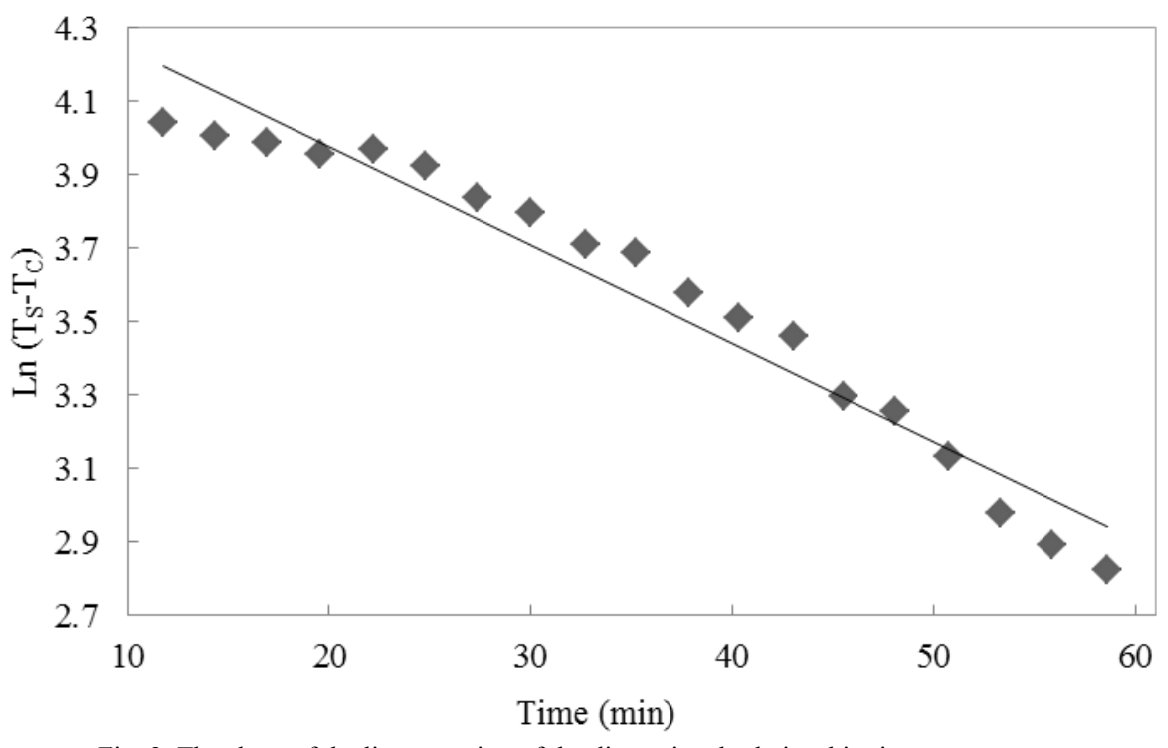

Fig. 2. The slope of the linear section of the dimensional relationship time-temperature.

The estimated thermal diffusivity of breadfruit is presented in Table 1 . The value obtained in this work was comparable to those obtained by Ayadi et al., [6] who found values of $5.1110^{-6} \mathrm{~m}^{2} / \mathrm{s}, 7.0210^{-6} \mathrm{~m}^{2} / \mathrm{s}, 6.0210^{-6}$ $\mathrm{m}^{2} / \mathrm{s}$ and $19.810^{-6} \mathrm{~m}^{2} / \mathrm{s}$ during the cooking of standard salami, Tunisian salami, salami with olives and turkey ham respectively. Other studies have reported estimates of thermal diffusivity very close to those found in this work, however, none for breadfruit. Kong et al., [14] said that the thermal diffusivity of lean beef ranged from $0.410^{-7} \mathrm{~m}^{2} / \mathrm{s}$ at $30^{\circ} \mathrm{C}$ to $1.310^{-7} \mathrm{~m}^{2} / \mathrm{s}$ at $66^{\circ} \mathrm{C}$. Markowski et al., [15] reported thermal diffusivity values obtained by analytical methods between approximately $3.5 \mathrm{~m}^{2} / \mathrm{s}$ and $4.510^{-7} \mathrm{~m}^{2} / \mathrm{s}$. Sheridan and Shilton [16] studied the influence of cooking and fat content on thermal diffusivity of ground beef patties by using infrared radiation technology and reported that it varied with cooking progress and fat content, ranging from $1.2210^{-7}$ $\mathrm{m}^{2} / \mathrm{s}$ to $1.8210^{-7} \mathrm{~m}^{2} / \mathrm{s}$.

Table 1. Thermal diffusivity for baking breadfruit.

\begin{tabular}{ccccc}
\hline Temperature $\left({ }^{\circ} \mathbf{C}\right)$ & $\mathbf{B}$ & $\mathbf{R}$ & $\mathbf{L}$ & Diffusivity $\left(\mathbf{D}_{\mathbf{a}} \mathbf{1 0}^{\mathbf{7}} \mathbf{~ m}^{2} / \mathbf{s}\right)$ \\
\hline 95 & -0.0268 & 0.015 & 0.05 & 6.45 \\
\hline
\end{tabular}

\section{CONCLUSIONS}

In the present work, a diffusivity value of $6.4510^{-7} \mathrm{~m}^{2} / \mathrm{s}$ was found during the cooking of cylinders of breadfruit. This study reported for the first times this value for breadfruit samples. In the present study, the thermal diffusivity was assumed to be constant during heat treatment, and the value calculated was consistent with values provided by other authors who worked with different food matrices. There is a need for further investigation of time-dependent changes in thermal diffusivity of these kinds of native products in Colombia and Latin América.

\section{REFERENCES}

[1] V. Kuete, P. Y. Ango, G. W. Fotso, G. D. Kapche, J. P. Dzoyem, A. G. Wouking, B. T. Ngadjui, and B. M. Abegaz, “Antimicrobial activities of the methanol extract and compounds from Artocarpus communis (Moraceae)," BMC Complementary and Alternative Medicine, vol. 11, no. 1, p. 42, Dec. 2011.

[2] N. A. Amusa, I. A. Kehinde, and O. A. Ashaye, "Bio-deterioration of breadfruit (Artocarpus Communis) in storage and its effects on the nutrient composition," African Journal of Biotechnology, vol. 1, no. 2, pp. 57-60, 2002.

[3] C. T. de Souza, S. A. R. Soares, A. F. S. Queiroz, A. M. P. dos Santos, and S. L. C. Ferreira, "Determination and evaluation of the mineral composition of breadfruit (Artocarpus altilis ) using multivariate analysis technique," Microchemical Journal, vol. 128, pp. 84-88, Sep. 2016.

[4] D. F. Tirado and D. Acevedo, "Heat and Matter Transfer during the Food Frying Process: Tilapia (Oreochromis niloticus) and Breadfruit (Artocarpus communis)," Información Tecnológica, vol. 26, no. 1, pp. 85-94, 2015.

[5] D. F. Tirado, D. Acevedo-correa, and P. M. Montero-castillo, "Dried fruit breadfruit slices by Refractive Window TM technique," Tecno Lógicas, vol. 19, no. 36, pp. 103-111, 2016.

[6] M. A. Ayadi, I. Makni, and H. Attia, "Thermal diffusivities and influence of cooking time on textural, microbiological and sensory characteristics of turkey meat prepared products," Food and Bioproducts Processing, vol. 87, no. 4, pp. 327-333, Dec. 2009.

[7] D. F. Tirado, D. Acevedo, and L. E. Guzmán, "Determination of Convective Coefficients of Heat Transfer During Frying of Sheet Tilapia (Oreochromis niloticus),” Información tecnológica, vol. 24, no. 6, pp. 13-14, 2013. 
[8] D. F. Tirado, D. Acevedo, and P. Puello, "Computational Determination of Heat Transfer Coefficient and Thermophysical Properties of Food," Información tecnológica, vol. 25, no. 3, pp. 53-58, 2014.

[9] B. A. M. Carciofi, J. Faistel, G. M. F. Aragão, and J. B. Laurindo, "Determination of thermal diffusivity of mortadella using actual cooking process data," Journal of Food Engineering, vol. 55, no. 1, pp. 89-94, Nov. 2002.

[10] P. Pittia, R. Furlanetto, M. Maifreni, F. Tassan Mangina, and M. Dalla Rosa, "Safe cooking optimisation by F-value computation in a semi-automatic oven," Food Control, vol. 19, no. 7, pp. 688-697, Jul. 2008.

[11] P. J. Torley, B. R. D'Arcy, and G. R. Trout, "The effect of ionic strength, polyphosphates type, pH, cooking temperature and preblending on the functional properties of normal and pale, soft, exudative (PSE) pork," Meat Science, vol. 55, no. 4, pp. 451-462, 2000.

[12] S. Tavman, I. H. Tavman, and S. Evcin, "Measurement of thermal diffusivity of granular food materials," International Communications in Heat and Mass Transfer, vol. 24, no. 7, pp. 945-953, 1997.

[13] M. Markowski, I. Bialobrzewski, M. Cierach, and A. Paulo, "Determination of thermal diffusivity of Lyoner type sausages during water bath cooking and cooling," Journal of Food Engineering, vol. 65, no. 4, pp. 591-598, Dec. 2004.

[14] J. Kong, T. Yano, J. Kim, S. Bae, and I. Kong, "Prediction of Effective Thermal Diffusivity of Fish and Meats," vol. 8451, no. October, 2017.

[15] M. Markowski, "Determination of thermal diffusivity of Lyoner type sausages during water bath cooking and cooling," vol. 65, pp. 591-598, 2004.

[16] P. S. Sheridan and N. C. Shilton, "Determination of the thermal diffusivity of ground beef patties under infrared radiation oven-shelf cooking," Journal of Food Engineering, vol. 52, no. 1, pp. 39-45, Mar. 2002.

\section{AUTHOR PROFILE}

Diego F. Tirado is a PhD student in Chemical Engineering at the Universidad Complutense de Madrid (Spain). Mr. Tirado has a bachelor degree in Food Engineering and a master degree in Environmental Engineering from the Universidad de Cartagena (Colombia).

Diofanor Acevedo-Correa works as a full-time professor at the Universidad de Cartagena. Dr. Acevedo has a doctoral degree in Food Engineering from the Universidad del Valle (Colombia). Furthermore, he has bachelor degrees in Food Engineering and Pharmaceutical Chemistry from the Universidad de Cartagena. He is full-time researcher of the Research Group Nutrición, Salud y Calidad Alimentaria (NUSCA).

Piedad Margarita Montero-Castillo works as a full-time professor at the Universidad de Cartagena. Dr. Montero-Castillo has a doctoral degree in Sciences from the Universidad Rafael Belloso Chacín (Venezuela). She also has a master degree in Food Science and Technology and a bachelor degree in Food Engineering from the Universidad del Zulia (Venezuela) and the Universidad de la Salle (Colombia), respectively. She is director of the Research Group NUSCA.

Shirley Cavadia-Puello works as a full-time professor at the Universidad de Cartagena. Currently, she is PhD student in Pharmaceutical Sciences at the Universidad de la Habana (Cuba) and she has a bachelor degree in Pharmaceutical Chemistry from the Universidad de Cartagena.

Diana C. Mantilla-Escalante is a PhD student in Food Sciences at the Universidad Autónoma de Madrid (Spain). Miss Mantilla-Escalante has a bachelor degree in Food Engineering from the Universidad de Cartagena and a master degree in Novel foods from the Universidad Autónoma de Madrid. 